University of Nebraska - Lincoln

DigitalCommons@University of Nebraska - Lincoln

Faculty Publications, Department of Psychology

Psychology, Department of

September 2005

\title{
Understanding Latino Children and Adolescents in the \\ Mainstream: Placing Culture at the Center of Developmental \\ Models
}

\author{
Marcela Raffaelli \\ University of Nebraska-Lincoln, mraffaelli1@unl.edu \\ Gustavo Carlo \\ University of Nebraska-Lincoln, carlog@missouri.edu \\ Miguel A. Carranza \\ University of Nebraska-Lincoln, mcarranza1@unl.edu \\ Gloria E. Gonzalez-Kruger \\ University of Nebraska-Lincoln, ggonzalezkruger2@unl.edu
}

Follow this and additional works at: https://digitalcommons.unl.edu/psychfacpub

Part of the Psychiatry and Psychology Commons

Raffaelli, Marcela; Carlo, Gustavo; Carranza, Miguel A.; and Gonzalez-Kruger, Gloria E., "Understanding Latino Children and Adolescents in the Mainstream: Placing Culture at the Center of Developmental Models" (2005). Faculty Publications, Department of Psychology. 118.

https://digitalcommons.unl.edu/psychfacpub/118

This Article is brought to you for free and open access by the Psychology, Department of at DigitalCommons@University of Nebraska - Lincoln. It has been accepted for inclusion in Faculty Publications, Department of Psychology by an authorized administrator of DigitalCommons@University of Nebraska - Lincoln. 
Published in NEW DIRECTIONS FOR CHILD AND ADOLESCENT DEVELOPMENT, no. 109 (Fall 2005), pp. 23-32. Copyright C Wiley Periodicals, Inc. Used by permission.
Demographic shifts in the U.S. population require developmental researchers to increase their attention to cultural diversity. Conceptual models that incorporate culturally relevant variables and focus on normative and positive development are needed to produce a more balanced understanding of Latino youth development.

\section{Understanding Latino Children and Adolescents in the Mainstream: Placing Culture at the Center of Developmental Models}

\author{
Marcela Raffaelli, Gustavo Carlo, Miguel A. Carranza, \\ Gloria E. Gonzalez-Kruger
}

The presence of Spanish-speaking people and their descendents in what are now parts of the United States of America dates back to the early sixteenth century. Despite this presence, Latino families and their children have been inadequately-and sometimes inaccurately - represented in the developmental literature. (In this chapter, the term Latino is used to refer to both male and female persons of Mexican, Puerto Rican, Cuban, and Central or South American origin or descent, regardless of race; Day, 1996.) It is our belief that to remedy this situation developmental scholars must do three things. First, explicit attention must be paid to cultural diversity between and within subgroups of Latino youth. Second, there is a need for research on normative and positive development in this population. Third, developmental models must meaningfully incorporate culturally relevant factors. In this essay, we elaborate on each of these suggestions and describe an integrated model we are using to guide our work on Latino youth development.

The authors are grateful for input from their colleagues in the Latino Research Initiative (LRI) and acknowledge the institutional support the LRI has received over the years. Manuscript preparation was partially supported by a Faculty Development Fellowship to Marcela Raffaelli from the College of Arts and Sciences, University of Nebraska-Lincoln, and by a Visiting Fellowship at the Key Centre for Women's Health in Society, School of Population Health, University of Melbourne. 


\section{Diversity of the Latino Population: Historical and Demographic Considerations}

Historical and demographic considerations point to variations between Latino youths and those from other ethnic groups, as well as among Latino subgroups, that have important implications for developmental research.

Colonization, Conquest, and Migration: A Brief History. The U.S. Latino population consists of Latino groups with varied histories, including long-term residents and more recent immigrants. For several centuries, territory that is now part of the United States was populated by indigenous peoples, Spanish colonists, and Mexican citizens. At one time, Spanish territories encompassed what are now the states of New Mexico, Texas, California, and Florida, as well as Puerto Rico and other Caribbean islands. During the eighteenth and nineteenth centuries, as wars were fought, treaties negotiated, and borders redrawn, Spanish Americans (primarily Mexicans) became an integral part of the United States. More recently, Latin American immigrants have followed a number of pathways to the United States. Since gaining independence, the United States has sought to influence events in Latin America through policy, diplomacy, and active intervention. The impact of these policies within Latin America is widespread; they also shape the experiences of Latinos in the United States. For example, during the second half of the twentieth century, citizens of some Latin American countries (an example is Cuba) were granted refugee status and resettlement assistance on entering the United States. In other countries (such as El Salvador), the United States supported repressive dictatorships, spurring a flow of often undocumented immigrants fleeing political violence and terror. Lack of economic opportunities in other nations (for instance, Mexico) led to a flow of migrant workers and undocumented immigrants that continues to this day. The diverse history of the Latino population in the United States would be expected to influence Latino youth development.

Demographic Characteristics of Latino Youth. According to the 2000 U.S. Census, Latino children and adolescents now represent 17 percent of the under-eighteen population (Lugalla \& Overturf, 2004), and it is projected that this proportion will increase to one-third by the year 2050 (U.S. Department of Health and Human Services, 2001). As shown in Table 3.1, Latino youths differ from those of other ethnic groups in ways that are likely to affect socialization and life experiences, ultimately influencing their development and well-being. For example, Latino youths are more likely to be foreign-born than white and black youths, more likely than white and Asian youths to live in poverty, and more likely than all other youths to have at least one parent who is not a high school graduate.

There are also significant variations between Latino subgroups that it is essential to consider (Baca Zinn, 1995; Gouveia, Carranza, \& Cogua, in press). Among them are geographic concentration patterns (for example, most $\mathrm{Cu}$ ban Americans live in the South, whereas Mexican Americans are concentrat-

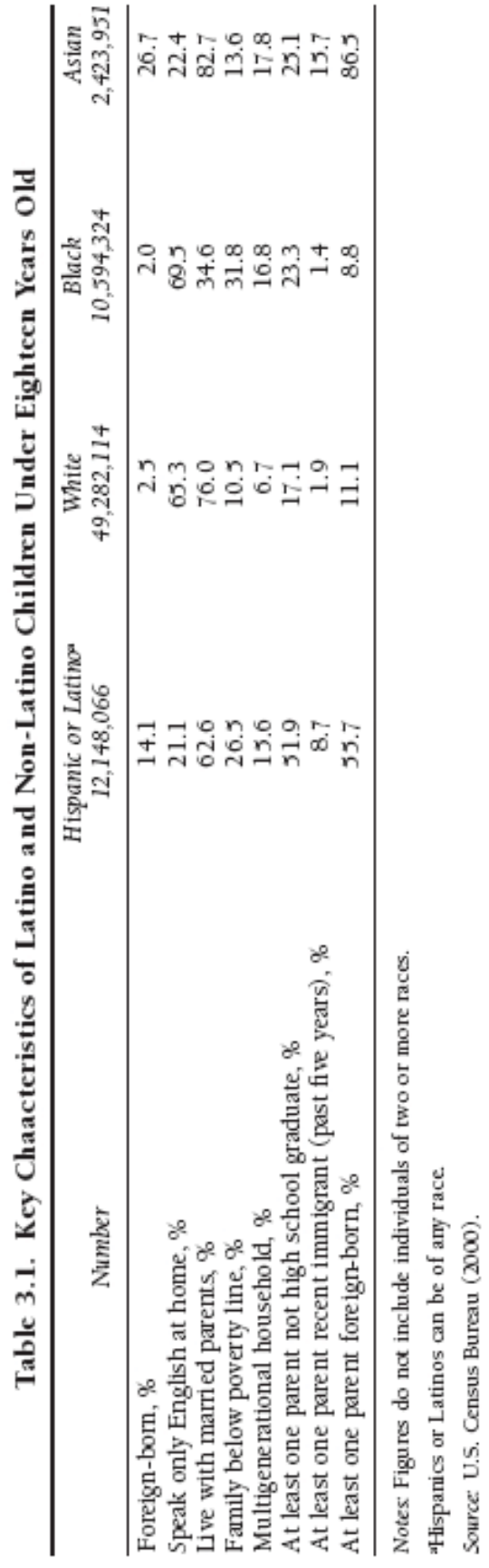


ed in the West), demographic characteristics (educational achievement, socioeconomic status), and immigration-related factors (generation of immigration, home language). Foreign-born Latinos vary in preimmigration experience (reason for departure), postimmigration experience (availability of ethnic enclaves), and individual characteristics (age on arrival and others).

These variations between Latino youths and those from other ethnic groups, as well as among Latino subgroups, have implications for children's and adolescents' development — and thus for developmental research.

Implications for Developmental Research. Despite the heterogeneity of the U.S. youth population as revealed in Table 3.1, researchers conducting general developmental studies have seldom collected the kind of information needed to examine within-group differences, Latinos included. However, to better understand development it is imperative that research studies take within-group variations into account. In the case of Latinos, it would be desirable to assess such basic indicators as Latino subgroup, generation of immigration, language used at home, and parental education and income (see also Umaña-Taylor \& Fine, 2001). This information can be used to describe the sample and if necessary control for subgroup differences in statistical analyses. Researchers should also temper their conclusions and avoid making unwarranted generalizations that assume Latinos form one amorphous group. These minor yet critical changes represent an important first step in broadening the knowledge base on Latino youth development.

\section{Studying Normative Development of Latino Youth}

A second step in improving our understanding of Latino youth involves overcoming a historical tendency to take a comparative and deficit perspective in research with Latinos (and other ethnically diverse populations; see for example Fisher et al., 2002; MacPhee, Kreutzer, \& Fritz, 1994). The comparative perspective typically defines European Americans as the norm and considers how other ethnic groups differ from that norm (Gonzalez-Kruger, Umaña-Taylor, Goldfarb, \& Villarruel, 2003). In consequence, within-group variations are ignored; moreover, deviations from the European American pattern are often interpreted as indicating inferiority rather than potentially legitimate differences in functioning (Fisher et al., 2002). As well, developmental research has been disproportionately focused on problems within Latino communities (such as teen pregnancy, school dropout rate; see García Coll et al., 1996; MacPhee et al., 1994). The net result is a lack of basic information about normative developmental experiences of Latino youth (McLoyd, Cauce, Takeuchi, \& Wilson, 2000; Parke \& Buriel, 1998; Rodriguez \& Morrobel, 2002).

There are encouraging signs that developmental scholars have seriously considered these concerns about research with ethnically diverse populations. For example, a recent analysis of articles published in the Journal of Research on Adolescence between 1999 and 2003 indicated that almost half of the articles had ethnically diverse samples (although only 8 percent of articles focused primarily on Latinos), fewer than 10 percent of all articles compared ethnic groups, and articles focusing on European Americans were more likely to be problem-focused than those involving ethnically diverse youth (Larson \& Cauce, 2004). There has also been a recent surge in research on normative development of Latino youths (and those of other ethnic groups; Fisher, Jackson, \& Villarruel, 1998; McLoyd \& Steinberg, 1998; Montero-Sieberth \& Villarruel, 2000). This recent scholarship represents an important step; however, it has also revealed the conceptual and empirical challenges researchers face when trying to take culture seriously in developmental research. We turn next to an examination of these issues.

\section{Representing Culture in Developmental Models}

Research on Latino youth has drawn primarily on two approaches for considering culture in the study of development. The first involves attempting to incorporate culture into existing models, and the second places culture at the center of the model. Each approach offers advantages and disadvantages and requires explicit decisions to be made regarding how to represent cultural variables.

Incorporating Culture into Existing Developmental Models. Attempts to develop universal models of development, or to examine common developmental experiences, are important sources of knowledge. However, efforts to develop comprehensive developmental theories that integrate cultural variables are rare (Rog off, 2003). Moreover, even when theorists incorporate culture into their models, researchers often fail to operationalize cultural variables adequately (McLoyd, 2004) For example, to permit incorporation of multiple ethnic groups, proxy variables such as education or birthplace or higher-order constructs such as individualism-collectivism are often used in lieu of culturally specific factors and values. In addition, mainstream developmental models often omit or relegate to the periphery factors highly salient to ethnic minority youth, such as experiences of racism (discrimination, prejudice) and social stratification (segregation; García Coll et al., 1996). Among Latino youth, issues of language and immigration are often particularly salient. Recently, in recognition of the difficulty of representing these factors within existing developmental models, scholars have begun to generate culture-specific models of development - a "paradigm shift" (García Coll \& Magnusson, 1999) that we believe can lead to a fuller understanding of Latino youth development.

Placing Culture at the Center. A number of scholars have developed models that allow them to examine specific developmental experiences among multiple ethnic groups, including Latinos. For example, Jean Phinney's program of research on ethnic identity builds on and extends traditional work on ego identity by examining how youngsters from various ethnic backgrounds come to grips with the role of ethnicity in their lives (Phinney, Cantu, \& Kurtz, 1997). The work of Carola and Marcelo Suárez-Orozco (2001) explores how individual and family 
functioning is affected by the experience of immigration. Catherine Cooper's program of research (1999) integrates culture into developmental perspectives on individuality and connectedness. This work underscores the value of developing models that explicate the role of culture in development

Others have addressed the need for comprehensive developmental models that accurately reflect ethnically diverse youngsters' lives. For example, García Coll and colleagues (1996) generated a comprehensive model for studying the development of children of color. Racism and social stratification variables are central to the model, reflecting the pervasive influence of these variables on children's immediate environments and developmental experiences. Our research team has been pursuing a multidisciplinary program of community-based research in the Midwest (Gonzalez-Kruger et al., 2000). We are articulating an integrated model for examining the development of Latino children and adolescents growing up in immigrant families. The model, depicted in Figure 3.1, draws on three theoretical frameworks: Laosa's model (1990) of the development of immigrant Latino children, Berry's model of the role of acculturative stress in Latino youth adjustment (Berry, Kim, Minde, \& Mok, 1987), and Lazarus and Folkman's model of stress and coping (1984).

Consistent with mainstream developmental models, we included a set of variables thought to influence children's cognitive and emotional development: characteristics of youngsters, their families and peer groups, and their everyday settings. Unlike traditional models, however, this model incorporates culturally relevant factors previously identified as important for Latino youth. For example, community and school context variables include the proportion of Latinos in the community or type of bilingual education program in school. Family, child, and peer characteristics encompass national origin, family form (transnational, binational, extended) age of child on arrival in the United States, and cultural background of peers. Cognitive and emotional factors include appraisals, identified in general models of stress and coping (Compas, 1987), and ethnic identity, an aspect of identity that is particularly salient for ethnically diverse youth (Phinney et al., 1997).

In addition, the model incorporates acculturative stress as an important intervening factor between antecedent and outcome variables. Acculturation is the process of adaptation that occurs when two cultural groups come into contact (Marín \& Marín, 1991); acculturative stress refers to physiological and psychological changes brought about by acculturation-related demands (Berry et al., 1987). The centrality of acculturative stress in our model reflects research findings that adaptation of Latino families to the dominant culture is associated with family conflict and individual stress perceptions (Gil \& Vega, 1996). Finally, the model explicitly recognizes that although Latinos experience adversity they also have strengths and resources. For example, they can draw on cultural belief systems that help them deal effectively with life challenges, among them values supporting family connectedness and respect for authority and elders. These cultural values and
Figure 3.1. Theoretical Model of Latino Youth Development

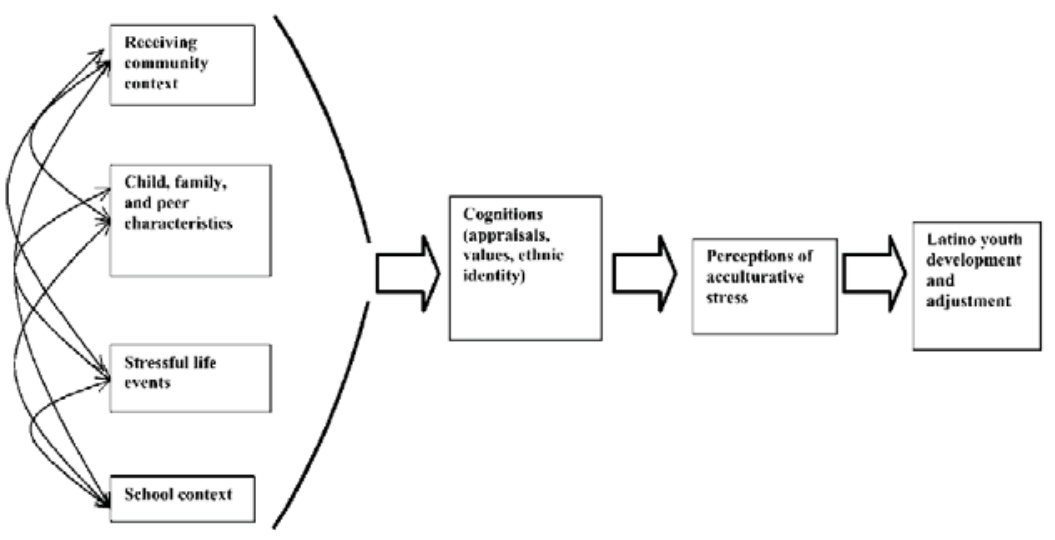

practices foster ethnic identity (Phinney et al., 1997) and collaborative behavior (Knight, Bernal, \& Carlo, 1995).

Although we have not yet tested the entire model within a single study, recent work by members of our team demonstrates the value of placing culture at the core of developmental research. For example, culturally relevant variables have emerged as important predictors of socialization practices in Latino families. In one set of analyses, parental national origin (Mexican versus other Latino origin) was linked to extent of communication about sexuality (Raffaelli \& Green, 2003); in another, acculturation and parental preference for same-ethnicity romantic partners were related with ethnic identity achievement among nineteen- to thirty-year-old Latino college students (Ontai-Grzebik \& Raffaelli, 2004). In an examination of linkages between characteristics of parent and peer relationships and behavioral outcomes, de Guzman and Carlo (2004) reported that Latino youths who reported secure attachment with peers and highly adaptable family systems exhibited a high level of prosocial behaviors. These findings highlight the potential of our integrated model for creating a framework for studying Latino youth development.

\section{Concluding Thoughts}

It is our belief that developmental research aimed at understanding Latino children and adolescents must take an explicit cultural focus. In this chapter, we have argued that scholars must attend not only to between-group differences but also to within-group diversity, examine normative developmental experiences, and develop models that meaningfully incorporate culturally relevant factors. Consid- 
erable progress toward these goals has been made in recent years. In particular, scholars have addressed many of the conceptual, ethical, and methodological is sues involved in studying ethnically diverse youth, and guidelines for conducting culturally competent studies have been published (Marín \& Marín, 1991). This literature is a solid basis on which to build in the future.

We hope that we have adequately conveyed the extent to which this literature is relevant not only for researchers who study Latinos but also for those who focus on mainstream populations. The U.S. population is undergoing its most dramatic transformation since the early nineteenth century. According to census projections, by the year 2050 just half the U.S. population will be "non-Hispanic White," down from three-quarters in 1990 (Day, 1996). Currently, one fifth of U.S. residents are either foreign-born or children of foreign-born parents, and this number will continue to grow. Thus, within the next twenty-five years all developmental research will either explicitly or implicitly involve the study of culturally and ethnically diverse youth. Failure to take these demographic realities into account will lessen the relevance of all developmental research.

\section{References}

Baca Zinn, M. (1995). Social science theorizing for Latino families in the age of diversity. In R. E. Zambrana (Ed.), Understanding Latino families: Scholarship, policy, and practice (pp. 177-189). Thousand Oaks, CA: Sage.

Berry, J. W., Kim, U., Minde, T., \& Mok, D. (1987). Comparative studies of acculturative stress. International Migration Review, 31, 491-511. Compas, B. E. (1987). Coping with stress during childhood and adolescence. Psychological Bulletin, 101, 393-403.

Cooper, C. R. (1999). Multiple selves, multiple worlds: Cultural perspectives on individuality and connectedness in adolescent development. In A. S. Masten (Ed.), The Minnesota symposia on child psychology, vol. 29: Cultural processes in child development (pp. 25 27). Hillsdale, NJ: Erlbaum.

Day, J. C. (1996). Population projections of the United States by age, sex, race, and hispanic origin: 1995 to 2050. (Current Population Reports, P25-1130.) Washington, DC: U.S. Census Bureau.

de Guzman, M.R.T., \& Carlo, G. (2004). Family, peer, and acculturative correlates of prosocial development among Latinos. Great Plains Research, 14, 185-202.

Fisher, C. B., Jackson, J. F., \& Villarruel, F. A. (1998). The study of African American and Latin American children and youth. In W. Damon (Series Ed) \& R. M. Lerner (Vol. Ed.), Handbook of child psychology, vol. 1: Theoretical models of human development (pp. 1145-1207). New York: Wiley.

Fisher, C. B., Hoagwood, K., Boyce, C., Duster, T., Frank, D. A., Grisso, T., Levine, R. J. Macklin, R., Spencer, M. B., Takanishi, R., Trimble, J. E., \& Zayas, L. H. (2002). Research ethics for mental health science involving ethnic minority children and youths. American Psychologist, 57, 1024-1040.

García Coll, C., Lamberty, G., Jenkins, R., Pipes McAdoo, H. P., Crnic, K., Wasik, B. H., \& Garcia, H. V. (1996). An integrative model for the study of developmental competencies in minority children. Child Development, 67, 1891-1914.
García Coll, C., \& Magnusson, K. (1999). Cultural influences on child development: Are we ready for a paradigm shift? In A. S. Masten (Ed.), The Minnesota symposia on child psychology, vol. 29: Cultural processes in child development (pp. 1-24). Mahwah, NJ: Erlbaum.

Gil, A. G., \& Vega, W. A. (1996). Two different worlds: Acculturation stress and adaptation among Cuban and Nicaraguan families. Journal of Social and Personal Relationships 13(3), 435-456.

Gonzalez-Kruger, G. E., Umaña-Taylor, A., Goldfarb, K., \& Villarruel, F. A. (2003). What do we REALLY know about Latino families? A content analysis of refereed publications. Poster session at the National Council on Family Relations (NCFR) Conference, Vancouver, British Columbia, Nov.

Gonzalez-Kruger, G., Zamboanga, B., Carlo, G., Raffaelli, M., Carranza, M. A., Hansen, D. Cantarero, R. \& Gajardo, J. (2000). The Latino research initiative: A multidisciplinary and collaborative community-university outreach and scholarship model. Great Plains Research, 10, 359-385.

Gouveia, L., Carranza, M. A., \& Cogua, J. (in press). The Great Plains migration: Mexicanos and Latinos in Nebraska. In V. Zuniga \& R. Hernandez-Leon (Eds.), New destinations of Mexican immigration in the United States: Community formation, local responses, and inter-group relations. New York: Sage.

Knight, G. P., Bernal, M. E., \& Carlo, G. (1995). Socialization and the development of cooperative, competitive, and individualistic behaviors among Mexican American children. In E. E. García \& B. McLaughlin (Eds.), Meeting the challenge of linguistic and cultural diversity in early childhood education (pp. 85-102). New York: Teachers College Press.

Laosa, L. (1990). Psychosocial stress, coping, and development of Hispanic immigrant children. In F. C. Serafica \& A. I. Schwebel (Eds.), Mental health of ethnic minorities (pp. 38-65). New York: Praeger.

Larson, R., \& Cauce, A. M. (n.d.). SRA and diversity: The results of a membership survey. Available at http://s-r-a.org/SRA.diver.report.htm . Retrieved Dec. 5, 2004.

Lazarus, R. S., \& Folkman, S. (1984). Stress, appraisal and coping. New York: Springer.

Lugalla, T., \& Overturf, J. (2004). Children and the households they live in: 2000. (Census 2000 Special Reports, CENSR-14.) Washington, DC: U.S. Census Bureau.

MacPhee, D., Kreutzer, J. C., \& Fritz, J. J. Infusing a diversity perspective into human development courses. Child Development, 1994, 65, 699-715.

Marín, G., \& Marín, B. V. (1991). Research with Hispanic populations. Thousand Oaks, CA: Sage.

McLoyd, V. C. (2004). Linking race and ethnicity to culture: Steps along the road from inference to hypothesis testing. Human Development, 47, 185-191.

McLoyd, V. C., Cauce, A. M., Takeuchi, D., \& Wilson, L. (2000). Marital processes and parental socialization in families of color: A decade review of research. Journal of Marriage and the Family, 62, 1070-1093.

McLoyd, V., \& Steinberg, L. (1998). Research on minority adolescents: Conceptual, methodological, and theoretical issues. Hillsdale, NJ: Erlbaum.

Montero-Sieberth, M., \& Villarruel, F. A. (Eds.) (2000). Making invisible Latino adolescents visible. New York: Falmer Press. 
Ontai-Grzebik, L. L., \& Raffaelli, M. (2004). Individual and social influences on ethnic identity among Latino young adults. Journal of Adolescent Research, 19, 559-575.

Parke, R. D., \& Buriel, R. (1998). Socialization in the family: Ethnic and ecological perspectives. In N. Eisenberg (Ed.), Handbook of child psychology, vol. 3, Social, emotional, and personality development (5th ed.) (pp. 463-552). New York: Wiley.

Phinney, J., Cantu, C. L., \& Kurtz, D. A. (1997). Ethnic and American identity as predictors of self-esteem among African American, Latino, and white adolescents. Journal of Youth and Adolescence, 26, 165-185.

Raffaelli, M., \& Green, S. (2003). Parent-adolescent communication about sex: Retrospective reports by Latino college students. Journal of Marriage and Family, 65, 474-481.

Rodriguez, M. C., \& Morrobel, D. (2002). A review of Latino youth development research and a call for an asset orientation. Hispanic Journal of Behavioral Sciences, 26, 107-127.

Rogoff, B. (2003). The cultural nature of human development. New York: Oxford University Press.

Suárez-Orozco, C., \& Suárez-Orozco, M. M. (2001). Children of immigrants. Cambridge, MA: Harvard University Press.

Umaña-Taylor, A., \& Fine, M. A. (2001). Methodological implications of grouping Latino adolescents into one collective ethnic group. Hispanic Journal of Behavioral Sciences, 23, 347-362.

U.S. Census Bureau. (2000). Census 2000 PHC-T-30 - characteristics of children under 18 years by age, for the United States, regions, states, and Puerto Rico: 2000. Available a http://www.census.gov/population/www/cen2000/phc-t30.html , tables 1 and 2. Retrieved Sept. 24, 2004.

U.S. Department of Health and Human Services. (2001). Mental health: Culture, race, and ethnicity. (Supplement to Mental health: A report of the Surgeon General.) Rockville, MD: U.S. Department of Health and Human Services.

MARCELA RAFFAELLI is professor of psychology and ethnic studies (Latino and Latin American studies) at the University of Nebraska-Lincoln.

GUSTAVO CARLO is professor of psychology at the University of Nebraska-Lincoln.

MIGUEL A. CARRANZA is associate professor of sociology and ethnic studies (Latino and Latin American studies) and director of the Institute for Ethnic Studies at the University of Nebraska-Lincoln.

GLORIA E. GONZALEZ-KRUGER is assistant professor in the Department of Family and Consumer Sciences and the Marriage and Family Therapy program at the University of Nebraska-Lincoln. 